\title{
Anticorpos anti-Neospora caninum em bovinos, ovinos e bubalinos no Estado do Rio Grande do Sul
}

\author{
Antibodies to Neospora caninum in cattle, sheep and water buffalo in \\ Rio Grande do Sul state, Brazil
}

\author{
Fernanda Silveira Flôres Vogel $^{1^{*}}$ Sandra Arenhart $^{2}$ \\ Fernando Viçosa Bauermann²
}

\begin{abstract}
- NOTA -
RESUMO

A infecção pelo Neospora caninum é distribuída mundialmente e tem sido considerada uma importante causa de abortos em bovinos, que são hospedeiros intermediários do protozoário. O presente artigo relata um estudo sorológico da

demonstrate that $N$. caninum infection is widespread among bovine and other ruminants in the state. Taken together with previous clinical and pathological reports, these results are indicative of the importance of the parasite as the etiological agent of reproductive failure in cattle in $R S$.
\end{abstract} infecção pelo $N$. caninum em 1.024 amostras de bovinos, ovinos e bubalinos, oriundos de 55 propriedades em 16 municípios do Estado do Rio Grande do Sul (RS). Anticorpos contra o agente foram detectados por um teste imunoenzimático do tipo ELISA em 11,4\% (89/781) das amostras de bovinos, em 14,6\% (24/164) dos bubalinos e em 3,2\% (2/62) dos ovinos. Bovinos soropositivos foram detectados em todos os municípios amostrados. Esses resultados demonstram que a infecção pelo $N$. caninum encontra-se amplamente difundida no rebanho bovino e também em outras espécies de ruminantes do Estado. Aliados a relatos clínicos e histopatológicos anteriores, esses resultados ressaltam a importância do $\mathbf{N}$. caninum como agente etiológico de falhas reprodutivas em bovinos no RS.

Palavras-chave: Neospora caninum, sorologia, epidemiologia, bovinos, bubalinos, ovinos.

\section{ABSTRACT}

The infection by Neospora caninum is distributed worldwide and has been considered an important cause of abortion in cattle, which are intermediate hosts of the parasite. The present article reports an serological survey of the N.caninum infection in 1024 serum samples of cattle, sheep and water buffalo from 55 herds in 16 counties of the state of Rio Grande do Sul (RS). Antibodies to the agent were detected by ELISA in $11.4 \%$ (89/781) bovine samples, in 14.6\% (24/ 164) water buffalo and in $3.2 \%$ (2/62) sheep sera. Positive cattle were detected in all tested counties. These results
Key words: Neospora caninum, serology, epidemiology, cattle, water buffalo, sheep.

O Neospora caninum (N. caninum) é um protozoário coccídio que tem sido considerado a principal causa de abortos em bovinos (ANDERSON et al., 1991). O agente foi descrito e caracterizado inicialmente em cães nos Estados Unidos (DUBEY et al., 1998) e, desde a sua descrição inicial, tem sido diagnosticado em várias espécies, inclusive em bovinos (DUBEY \& LINDSAY, 1996). A enfermidade associada à infecção por esse parasita é denominada de neosporose.

O ciclo biológico do Neospora caninum foi primeiramente descrito por MCALLISTER et al. (1998) e envolve a presença de hospedeiros definitivos e intermediários. O ciclo do protozoário envolve três estágios infecciosos: os bradizoítos, os taquizoítos e os esporozoítos. Os taquizoítos e os bradizoítos são estágios intracelulares encontrados no hospedeiro intermediário, enquanto que os esporozoítos se desenvolvem dentro dos oocistos no processo de esporulação (DUBEY, 2003).

\footnotetext{
1*Departamento de Medicina Veterinária Preventiva (DMVP), Universidade Federal de Santa Maria (UFSM), 97105-900, Santa Maria, RS, Brasil. E-mail: fervogel@smail.ufsm.br. Autor para correspondência.

${ }^{2}$ Curso de Medicina Veterinária, UFSM, Santa Maria, RS, Brasil.
} 
O cão é o hospedeiro definitivo que se caracteriza por excretar oocistos do protozoário nas fezes que no ambiente esporulam. Os hospedeiros intermediários ingerem os oocistos esporulados e nestes ocorre o desenvolvimento de cistos teciduais. O N. caninum tem como hospedeiros definitivos principais os cães domésticos (MCALLISTER et al., 1998). Recentemente, coiotes foram sugeridos como possíveis hospedeiros definitivos, pois oocistos do parasita foram detectados em suas fezes (GONDIM et al., 2004). O N. caninum apresenta vários possíveis hospedeiros intermediários, incluindo ruminantes domésticos e silvestres, eqüinos, caninos, entre outros. Entre os hospedeiros intermediários, os mais importantes parecem ser os bovinos. Até o presente, os bovinos são considerados os mais importantes hospedeiros intermediários utilizados por este protozoário (MCALLISTER et al., 1998). No entanto, a transmissão horizontal, ou seja, através da ingestão de oocistos, não é freqüente em bovinos. Em bovinos, o protozoário se mantém através da transmissão vertical. Nesse sentido, a neosporose possui uma grande importância econômica, principalmente devido às perdas reprodutivas que produz, incluindo retornos ao cio, com intervalos regulares ou irregulares, abortos, nascimento de bezerros fracos e inviáveis, com sinais neurológicos, ou persistentemente infectados (DUBEY \& LINDSAY, 1996). Os bezerros persistentemente infectados são muito importantes na epidemiologia da enfermidade e constituem-se nos principais responsáveis pela manutenção do agente em um rebanho (DUBEY, 2003). Esses animais são clinicamente normais, são soropositivos e abrigam o parasita encistado em vários tecidos, sendo considerados portadores do agente. A reativação da infecção em fêmeas prenhes persistentemente infectadas, provavelmente devido à imunossupressão fisiológica da gestação, pode resultar em transmissão transplacentária do agente ao feto (INNES et al., 2002). $\mathrm{O}$ aborto é a consequiência reprodutiva mais evidente da neosporose em fêmeas prenhes e ocorre mais freqüentemente no segundo trimestre de gestação (BIELSA et al., 2004).

A neosporose apresenta distribuição mundial e tem sido descrita inclusive no Brasil. Os primeiros estudos sorológicos da infecção no país foram realizados em bovinos leiteiros no Estado de São Paulo e em bovinos de corte no Mato Grosso do Sul (BRAUTIGAM et al., 1996). Após isso, vários estudos sorológicos foram realizados em diferentes Estados, detectando índices de prevalência variáveis entre 6,8\% (COSTAet al., 2001) e 67,8\% (BELO et al., 1999). No Rio Grande do Sul, CORBELLINI et al. (2002) detectaram uma prevalência de $11,2 \%$ (de um total de 223 amostras) de animais soropositivos para o N.caninum pelo uso da técnica de imunofluorescência indireta. RAGOZO et al. (2003) detectaram $20 \%$ de bovinos soropositivos no Estado, de um total de 140 amostras testadas. Muitos desses estudos foram realizados com amostras de propriedades com problemas reprodutivos, ou com um número muito pequeno de amostras e, portanto, devem ser analisados com cautela, pois podem ser amostras viciadas e assim não devem ser consideradas representativas da situação epidemiológica atual da infecção no rebanho brasileiro.

A real distribuição e a frequiência da infecção pelo $N$. caninum no rebanho requer a realização de estudos mais abrangentes e com amostragens planificadas e sistemáticas. O presente estudo teve como objetivo contribuir para o conhecimento da realidade epidemiológica da infecção pelo $N$. caninum no RS pela detecção de anticorpos contra o agente em ruminantes. Para isso, foram utilizadas 1.007 amostras de sangue coletadas de ruminantes (781 de bovinos, 62 de ovinos e 164 de bubalinos), pertencentes a 55 propriedades em 16 municípios do RS (Tabela 1). Devese deixar claro que essas amostras foram coletadas por técnicos da Secretaria da Agricultura do Estado do RS, para monitoramento sorológico da resposta à vacinação contra o vírus da Febre Aftosa. A coleta destas amostras foi baseada em uma amostragem planificada enfocando a Febre Aftosa. No entanto, a grande vantagem da amostragem utilizada para pesquisa de anticorpos anti- $N$. caninum, o que é de grande importância do ponto de vista epidemiológico, é que não são amostras que chegaram para diagnóstico devido ao fato de o rebanho apresentar problemas reprodutivos além do número amostrado.

As amostras de soro foram testadas para a presença de anticorpos anti- $\boldsymbol{N}$. caninum através do teste ELISA indireto - CHEKIT $^{\odot a}$, realizado e interpretado de acordo com instruções do fabricante.

O resumo dos resultados da sorologia está apresentado na tabela 1 . Além da presença de animais soropositivos em todos os municípios, pode-se observar uma ampla variação dos índices de positividade nos bovinos de diferentes municípios. Considerando-se o número de bovinos soropositivos com relação ao total coletado, a prevalência de animais com anticorpos anti-N. caninum foi de 11,4\% (89/781) em bovinos, de $14,6 \%$ (24/164) em bubalinos e de $3,2 \%$ (2/62) em ovinos.

Os estudos sorológicos da infecção pelo $N$. caninum no Brasil têm demonstrado índices de soropositividade variáveis. Os estudos que detectaram prevalências altas geralmente utilizaram amostras de rebanhos-problema, o que justifica os altos índices de positividade. Obviamente, a probabilidade de se detectar uma alta freqüência de animais soropositivos para o $N$. caninum em rebanhos com problemas 
Tabela 1 - Prevalência de anticorpos anti-N. caninum em bovinos, ovinos e bubalinos, por município, no Estado do Rio Grande do Sul.

\begin{tabular}{|c|c|c|c|}
\hline Municipio & Espécie & Número de amostras & Positivas $(\%)$ \\
\hline Alecrim & Bovinos & 50 & $6(12 \%)$ \\
\hline Augusto Pestana & Bovinos & 39 & $1(2,5 \%)$ \\
\hline Bagé & Bovinos & 31 & $2(6,4 \%)$ \\
\hline Cruz Alta & Bovinos & 31 & $2(6,4 \%)$ \\
\hline \multirow{2}{*}{ Itaqui } & Bovinos & 30 & $8(26,6 \%)$ \\
\hline & Ovinos & 10 & $1(10 \%)$ \\
\hline \multirow{2}{*}{ Jóia } & Bubalinos & 60 & $5(8,3 \%)$ \\
\hline & Ovinos & 22 & 0 \\
\hline Novo Machado & Bovinos & 37 & $9(24,3 \%)$ \\
\hline Porto Lucena & Bovinos & 23 & $1(4,3 \%)$ \\
\hline Porto Mauá & Bovinos & 23 & $5(21,7 \%)$ \\
\hline Porto Vera Cruz & Bovinos & 24 & $5(20,8 \%)$ \\
\hline Quaraí & Bovinos & 12 & $2(16,6 \%)$ \\
\hline \multirow{3}{*}{ Santana do Livramento } & Bovinos & 275 & $11(4 \%)$ \\
\hline & Bubalinos & 51 & $10(19,6 \%)$ \\
\hline & Ovinos & 10 & $1(10 \%)$ \\
\hline Santa Maria & Bovinos & 11 & $3(27,3 \%)$ \\
\hline São Borja & Bovinos & 30 & $4(13,3 \%)$ \\
\hline Tenente Portela & Bovinos & 30 & $2(6,7 \%)$ \\
\hline \multirow{3}{*}{ Uruguaiana } & Bovinos & 135 & $28(20,7 \%)$ \\
\hline & Bubalinos & 53 & $9(17 \%)$ \\
\hline & Ovinos & 20 & 0 \\
\hline Total & & 1007 & $115(11,4 \%)$ \\
\hline Bovinos & & 781 & $89(11,4 \%)$ \\
\hline Bubalinos & & 164 & $24(14,6 \%)$ \\
\hline Ovinos & & 62 & $2(3,2 \%)$ \\
\hline
\end{tabular}

reprodutivos é maior, quando comparada a rebanhos sem histórico de problemas reprodutivos. STOBBE (1999) detectou prevalência de 53,6\% (45/84) em animais com histórico de aborto no Estado de SP, comparado com uma prevalência de 26,2\% (22/84) em rebanhos sem histórico de problemas reprodutivos. Os índices de positividade detectados no presente estudo $(11,3 \%)$ foram semelhantes aos observados por CORBELLINI et al. (2002) em 223 bovinos leiteiros no RS $(11,2 \%)$ e não muito diferentes dos obtidos por RAGOZO et al. (2003) em bovinos de leite (13\%) e corte $(15 \%)$ no Estado. No presente estudo, as amostras foram coletadas indiscriminadamente de rebanhos leiteiros e de corte, independentemente de apresentarem ou não histórico de problemas reprodutivos. Com base nesses fatos, aliado ao número de amostras testadas, pode-se considerar estes resultados como um bom indicativo da situação atual da população bovina do Estado em geral com relação à infecção pelo Neospora caninum .

Existem poucos estudos sobre a presença da infecção por N.caninum em bubalinos, embora tenha sido sugerido que a neosporose também pode determinar perdas reprodutivas nessa espécie. $\mathrm{O} N$. caninum já foi isolado de bubalinos (RODRIGUES et al., 2004) e, atualmente, investiga-se a importância dessa espécie na epidemiologia da enfermidade, uma vez que muitas vezes os bubalinos são criados juntamente com os bovinos (GENNARI, 2004). Nesse sentido, já foi demonstrado que bovinos podem ser infectados com isolados de $\boldsymbol{N}$. caninum de bubalinos (RODRIGUES et al., 2004). Estudos sorológicos nessa espécie demonstraram índices de 36,5\% de soropositivos na Bahia (GONDIM et al., 1999), de 56\% (SOUZA et al., 2001) e de 64\% (FUJJI et al., 2001) em SP, de 70,9\% no Pará (GENNARI et al., 2005). No presente estudo, foram detectados $14,6 \%$ de animais positivos, em três propriedades testadas.

Sabe-se que a Neosporose em ovinos não apresenta a mesma relevância que em bovinos. No entanto, em propriedades em que são criados juntamente com bovinos, os ovinos podem eventualmente participar da epidemiologia da infecção. Os dados de prevalência em ovinos detectados no presente estudo $(3,2 \%)$ situam-se entre valores de 0,45\% (HELMICK et al., 2002) e 9\% (FIGLIUOLO et al., 2004), detectados anteriormente. 
Em resumo, os resultados da sorologia realizada no presente estudo demonstraram que a infecção pelo N.caninum está disseminada, em níveis de prevalência moderados, no rebanho bovino do RS, e que envolve também outras espécies de ruminantes. Aliados aos relatos clínico-patológicos de problemas reprodutivos associados ao agente, esses resultados sugerem que a infecção pelo N.caninum representa um problema sanitário e econômico importante para a reprodução bovina no RS. Por isso, sistemas de diagnóstico e monitoramento de rebanhos, assim como alternativas para o controle da infecção, devem ser considerados prioritários para se melhorar os índices reprodutivos de gado de corte e leite no Estado.

\section{AGRADECIMENTOS}

À empresa AKZO NOBEL Divisão Intervet, pelo fornecimento dos testes ELISA para a detecção de anticorpos anti-Neospora caninum.

Ao Prof. Eduardo Furtado Flores, pelo auxílio fundamental na redação deste artigo.

\section{FONTES DE AQUISIÇÃO}

${ }^{a}$ Kit Elisa para diagnóstico de anticorpos anti-Neospora caninum: Chekit - Bommeli Diagnostics. Stationsstrasse 12 CH-3097 Liebefeld-Bern. www.bommeli.com

\section{REFERÊNCIAS}

ANDERSON, M.L. et al. Neospora-like protozoan infection as a major cause of abortion in California dairy cattle. Journal of the American Veterinary Medical Association, v.198, p.241-244, 1991

BELO, M.A.A. et al. Presença de anticorpos contra o Neospora caninum em bovinos com histórico de aborto não diagnosticados etiologicamente. In: SEMINÁRIO BRASILEIRO DE PARASITOLOGIA VETERINÁRIA, 1999, Salvador. Anais... Salvador: Colégio Brasileiro de Parasitologia Veterinária, 1999. p. 229 .

BIELSA, J.M. et al. Controle de neosporose em bovinos com Bovilis ${ }^{\circ}$ Neoguard: a experiência de campo. Revista Brasileira de Parasitologia Veterinária, v.13, n.1, p.34-37, 2004.

BRAUTIGAM, F.E. et al. Resultados de levantamento sorológico ara espécie Neospora em bovinos de corte e leite. In: CONGRESSO PANAMERICANO DE CIÊNCIAS VETERINÁRIAS, 15., 1996, Campo Grande. Anais... Campo Grande: PANVET, 1996. p.284.

CORBELLINI, L.G. et al. Neosporosis as a cause of abortion in dairy cattle in Rio Grande do Sul, southern Brazil. Veterinary Parasitology, v.103, p.195-202, 2002.

COSTA, G.H.N. et al. Freqüência de anticorpos anti-Neospora caninum e anti-Toxoplasma gondii em soros de bovinos pertencentes aos estados de São Paulo e Minas Gerais. Semina, v.22, p.57-62, 2001.
DUBEY, J.P., LINDSAY, D.S. A review of Neospora caninum and neosporosis. Veterinary Parasitology, v.67, n.1, p.159, 1996

DUBEY, J.P. et al. Hydrocephalus associated with Neospora caninum-infection in an aborted bovine fetus. Journal of Comparative Parasitology, v.118, p.169-173, 1998.

DUBEY, J.P. Review of Neospora caninum and neosporosis in animals. Korean Journal Parasitology, v.41, n.1, p.1-16, 2003.

FIGLIUOLO, L.P.C et al. Prevalence of anti- Toxoplasma gondii and Neospora caninum antibodies in ovine from São Paulo State, Brazil. Veterinary Parasitology, v.123, n.3-4, p.161-166, 2004

FUJII, T.U. et al. Seroprevalence of Neospora caninum in female water buffaloes (Bubalus bubalis) from the southeastern region of Brazil. Veterinary Parasitology, v.99, p.331-334, 2001 .

GENNARI, S.M. Neospora caninum no Brasil: situação atual da pesquisa. Revista Brasileira de Parasitologia Veterinária, v.13, n.1, p.23-28, 2004.

GENNARI, S.M. et al. Ocurrence of antibodies anti Neospora caninum in water buffaloes (Bubalus bubalis) from north region of Brazil. Veterinary Parasitology, v.134, n.1-2, p.169171,2005

GONDIM, L.F.P. et al. Soroprevalence of Neospora caninum in dairy cattle in Bahia, Brazil. Veterinary Parasitology, v.86, p.71-75, 1999.

GONDIM, L.F.P. et al. Coiyotes (Canis latrans) are definite hosts of Neospora caninum. Internacional Journal for Parasitology, v.34, p.159-161, 2004.

HELMICK, B. et al. Serological investigation of aborted sheep and pigs for infection by Neospora caninum. Research in Veterinary Science, v.73, p.187-189, 2002.

INNES, E.A. et al. Immune responses to Neospora caninum and prospects for vaccination. Trends in Parasitology, v.18, p.497- 504, 2002

MCALLISTER, M.M. et al. Dogs are definitive hosts of Neospora caninum. Internacional Journal for Parasitology, v.28, n.9, p.1473-78, 1998.

RAGOZO, A.M.A. et al. Ocorrência de anticorpos antiNeospora caninum em soros bovinos procedentes de seis Estados brasileiros. Revista Brasileira de Parasitologia Veterinária, v.12, n.1, p.33-37, 2003.

RODRIGUES, A.A.R. et al. Shedding of Neospora caninum oocysts by dogs fed tissues from naturally infected water buffaloes (Bubalus bubalis) from Brazil. Veterinary Parasitology, v.124, n.3-4, p.139-150, 2004.

SOUZA, S.L.P. et al. Detecção de anticorpos anti-Neospora caninum e Toxoplasma gondii em soros de bubalinos (Bubalus bubalis) no estado de São Paulo, Brasil. Semina, v.22, p.3948, 2001.

STOBBE, N.S. Estudo interativo entre a presença de anticorpos anti-Neospora caninum e a ocorrência de abortamentos em bovinos no noroeste do Estado de São Paulo. 1999. 44f. Tese (Doutorado em parasitologia)Faculdade de Medicina Veterinária e Zootecnia, Universidade de São Paulo, São Paulo. 